Article

\title{
The Antidepressant-like Effect of Flavonoids from Trigonella Foenum-Graecum Seeds in Chronic Restraint Stress Mice via Modulation of Monoamine Regulatory Pathways
}

\author{
Jiancheng Wang, Cuilin Cheng *, Chao Xin and Zhenyu Wang * \\ Harbin Institute of Technology, 92 West Dazhi Street, Nangang District, Harbin 150001, China; \\ wangjiancheng3612@126.com (J.W.); wjc2386026898@163.com (C.X.) \\ * Correspondence: ccuilin@hit.edu.cn (C.C.); wzy219001@163.com (Z.W.); \\ Tel.: +86-1884-578-1315 (C.C.); +86-1303-996-0001 (Z.W.)
}

Academic Editor: Thomas Efferth

Received: 27 February 2019; Accepted: 19 March 2019; Published: 20 March 2019

\begin{abstract}
Fenugreek (Trigonella Foenum-Graecum) seeds flavonoids (FSF) have diverse biological activities, while the antidepressant-like effect of FSF has been seldom explored. The aim of this study was to evaluate the antidepressant-like effect of FSF and to identify the potential molecular mechanisms. LC-MS/MS was used for the determination of FSF. Chronic restraint stress (CRS) was used to establish the animal model of depression. Observation of exploratory behavior in the forced swimming test (FST), tail suspension test (TST) and sucrose preference test (SPT) indicated the stress level. The serum corticosterone (CORT) level was measured. The monoamine neurotransmitters (5-HT, NE and DA) and their metabolites, as well as monoamine oxidase A (MAO-A) enzyme activity in the prefrontal cortex, hippocampus and striatum, were evaluated. The protein expression levels of KLF11, SIRT1, MAO-A were also determined by western blot analysis. The results showed that FSF treatment significantly reversed the CRS-induced behavioral abnormalities, including reduced sucrose preference and increased immobility time. FSF administration markedly restored CRS induced changes in concentrations of serum corticosterone, prefrontal cortex neurotransmitters (NE, 5-HT and $\mathrm{DA})$, hippocampus neurotransmitters (NE, 5-HT and DA) and striatum neurotransmitters (NE). FSF treatment exhibited significant inhibition of MAO-A activity in the prefrontal cortex and hippocampus. FSF also significantly down-regulated the KLF11, SIRT1 and MAO-A protein expression levels in the prefrontal cortex and hippocampus. These findings indicate that FSF could exhibit an antidepressant-like effect by down-regulating the KLF11/SIRT1-MAO-A pathways, inhibiting MAO-A expression and activity, as well as up-regulating monoamine neurotransmitters levels.
\end{abstract}

Keywords: flavonoids; depression; monoamine neurotransmitters; monoamine oxidase A; KLF11; SIRT1

\section{Introduction}

Depression, one of the most common mood disorders, has become one of the major causes of disability and will be the second most significant cause of disease by 2030 [1,2]. Depression is characterized by mood disturbances, cognitive functions, anhedonia and attentional deficits [3]. In the modern world, an estimated $17-21 \%$ of the population has suffered from depression [4], and rapid social development will increase the risk factors that cause depression.

Although the pathogenesis of depression is still intangible, some hypotheses have been put forward. For example, the monoamine neurotransmitter hypothesis involves the core concepts of depression [5]. Early studies have shown that lack of monoamine neurotransmitters, such as norepinephrine (NE), 5-hydroxytryptamine (5-HT), dopamine (DA), etc. in the central and peripheral 
regions is a major cause of depression [6]. Lower concentrations of NE, 5-HT and DA, as well as higher concentrations of 5-hydroxyindoleacetic acid (5-HIAA, 5-HT metabolites), homovanillic acid (HVA, DA metabolites) and 3,4-dihydroxyphenylacetic acid (DOPAC, DA metabolites) were found in the different brain regions with depression. Monoamine oxidases(MAO) enzymes, including two types of MAO terms as MAO-A and MAO-B, could catabolize monoamine neurotransmitters and regulate their levels [5]. Type A monoamine oxidase (MAO-A) catabolizes monoamine neurotransmitters including NE, 5-HT and DA, the abnormally elevated MAO-A activity could result in decreased levels of monoamine transmitters, which in turn leads to depression [7]. Hence, brain MAO-A plays a major role in depressive disorders, could be considered as a target for the treatment of depression $[8,9]$.

The cytostatic protein Kruppel-likefactor11 (KLF11) is a member of the Sp1/KLF zinc finger transcription factor family, its main role is not only to inhibit cell growth and induce apoptosis, but also to act as a MAO transcriptional activator [10]. KLF11 can increase brain MAO-A expression through SP1 binding sites, and play an important role in stress-related depressive disorders [11]. KLF11 protein expression was significantly increased in the frontal cortex and hippocampus, however, no significant changes of KLF11 expression were detected in the striatum and hypothalamus, which suggested that KLF11 protein expression is selectively affected by chronic stress [12]. Silent mating type information regulation 2 homolog 1 (SIRT1) is a protein in the Sirtuin family, and recent studies suggested that SIRT1 protein could affect monoamine transmitter levels in the brain by activating MAO-A transcription, thus the dysregulation of SIRT1 may be involved in depression [13,14].

Stress affects people of all ages, genders and environments, leading to physical and mental health problems. Stress can cause structure degradation and function impairment of the brain, and is an unavoidable phenomenon that is one of the leading risk factors for the development of major depression [15]. The chronic restraint stress (CRS) model is a very common animal model used to mimic the development and progress of clinical depression [16]. Several abnormal behavioral phenotypes such as growth retardation, reduction in sucrose preference and increasing of immobility time are found in the CRS model [17]. Neurotransmitter transmission and metabolic disorder occurred in the prefrontal cortex, hippocampus, striatum, hypothalamus and amygdala in CRS-induced mice [18,19].

It has been reported that clorgyline, toloxatone and moclobemide could be used as MAO-A inhibitors, while the side effects, including high cost, a long cycle and low success rate of the drugs noted above could not be ignored. Fortunately, many researchers found that flavonoids, coumarins and alkaloids and their derivatives from natural herbal medicines exhibited strong MAO-A inhibition ability [20]. These natural products became good models for screening MAO-A inhibitors, as they usually show a synergistic manner with antidepressant-like effects, and have almost no side effects [21,22]. A variety of plant extracts and isolated components with MAO-A inhibitory activity are used for depression treatment, and have been extensively studied in many cases, such as Gynostemma pentaphyllum [23], Trigonella foenum-graecum seeds [24], Polygala tenuifolia [25], Ginkgo biloba leaves [26], Astragalus membranaceus [27], Radix paeoniae alba [28] and Suanzaorenhehuan Formula [29], etc. In certain cases, attempts to isolate the active monomers from plant extracts eventually may be worth the loss since pharmacological activities often rely on synergistic and polyvalent interactions between plant components [30]. Therefore, in this study we screened the MAO-A inhibitors from seven plant extracts in vitro and determined that the flavonoids from Trigonella foenum-graecum seeds (FSF) had the most effective inhibition ability. Then the antidepressant-like effects and mechanisms of FSF in the chronic restraint stress mice model were investigated through behavioral evaluation and neurochemical analysis methods. These data indicate that FSF inhibited the expression and activity of MAO-A by regulating the KLF11/SIRT1-MAO-A signaling pathways and decreased the levels of monoamine neurotransmitters, thereby exhibiting an antidepressant-like effect. 


\section{Results}

\subsection{The Results of Screening for MAO-A Inhibitors in Vitro}

As depicted in Figure 1, with the increase of the concentration of ethanol extracts from 7 plants, the inhibition rate of MAO-A gradually increased in the range of $0.25-32 \mathrm{mg} / \mathrm{mL}$. According to Table 1 , the ethanol extract of Trigonella foenum-graecum seeds $\left(\mathrm{IC}_{50}=2.968 \mathrm{mg} / \mathrm{mL}\right)$ showed the most significant inhibition MAO-A ability. After purification by HP-20 macroporous resin and Sephadex LH-20, we found that Fr 3-3 $\left(\mathrm{IC}_{50}=0.191 \mathrm{mg} / \mathrm{mL}\right)$ had the most effective MAO-A inhibition ability, but had a lower ability than clorgiline (a selective MAO-A inhibitor, $\mathrm{IC}_{50}=0.016 \mathrm{mg} / \mathrm{mL}$ ).

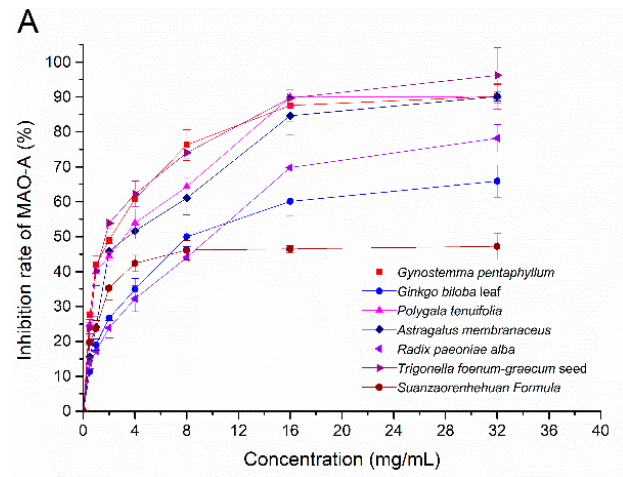

C

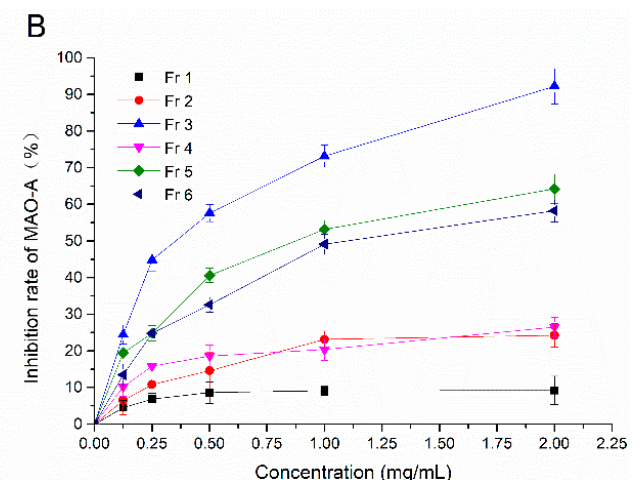

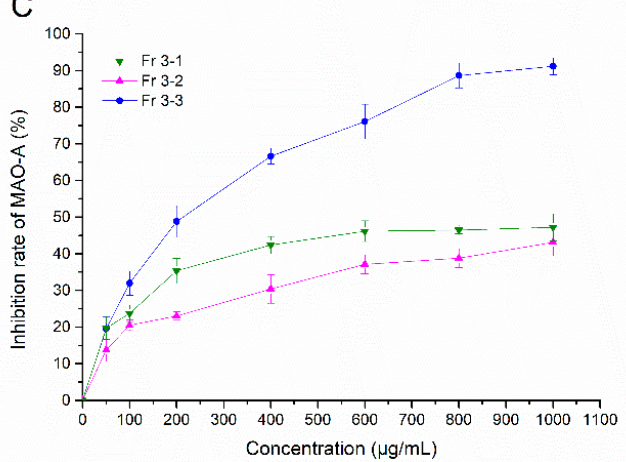

Figure 1. MAO-A inhibition rates of different concentration of samples. (A) Plant ethanol extracts. (B) Primary fractions by HP-20 macroporous resin from the ethanol extract of Trigonella foenum-graecum seeds. (C) Secondary fractions by Sephadex LH-20 from Fr 3.

Table 1. $\mathrm{IC}_{50}$ values of MAO-A inhibition rates.

\begin{tabular}{cc}
\hline Ethanol Extracts/Purified Fractions & MAO-A Inhibition IC50 (mg/mL) \\
\hline Gynostemma pentaphyllum & 3.322 \\
Ginkgo biloba leaves & 16.445 \\
Polygala tenuifolia & 4.470 \\
Trigonella foenum-graecum seeds & 2.968 \\
Astragalus membranaceus & 7.682 \\
Radix paeoniae alba & 12.568 \\
Suanzaorenhehuan Formula & 27.827 \\
Fr 1 & 21.022 \\
Fr 2 & 7.152 \\
Fr 3 & 0.947 \\
Fr 4 & 8.240 \\
Fr 5 & 2.377 \\
Fr 6 & 2.862 \\
Fr 3-1 & 0.985 \\
Fr 3-2 & 1.878 \\
Fr 3-3 & 0.191 \\
Clorgiline & 0.016 \\
\hline
\end{tabular}




\subsection{LC-MS/MS Analysis}

Tentative characterization of Fr3-3 was determined by LC-MS/MS analysis in the positive mode. The total ion chromatogram (TIC) of Fr 3-3 was shown in Figure 2. Supported by the fragment pattern (Table 2, Supplementary Materials Figure S1), as well as previous reports, the corresponding compounds were initially determined. Nine representative peaks (Table 2) were identified as Kaempferol 3-(p-coumaryl) glucoside [31], Quercetin 4'-O- $\beta$-d-glucopyranoside [32], Apigenin 4',7-Odiglucoside [33], Schaftoside [34], Isoschaftoside [35] and Apigenin 8-C- $\alpha$-D-glucopyranoside [36], respectively, indicating that Fr3-3 with MAO-A inhibition ability includes fenugreek seeds flavonoids (FSF).

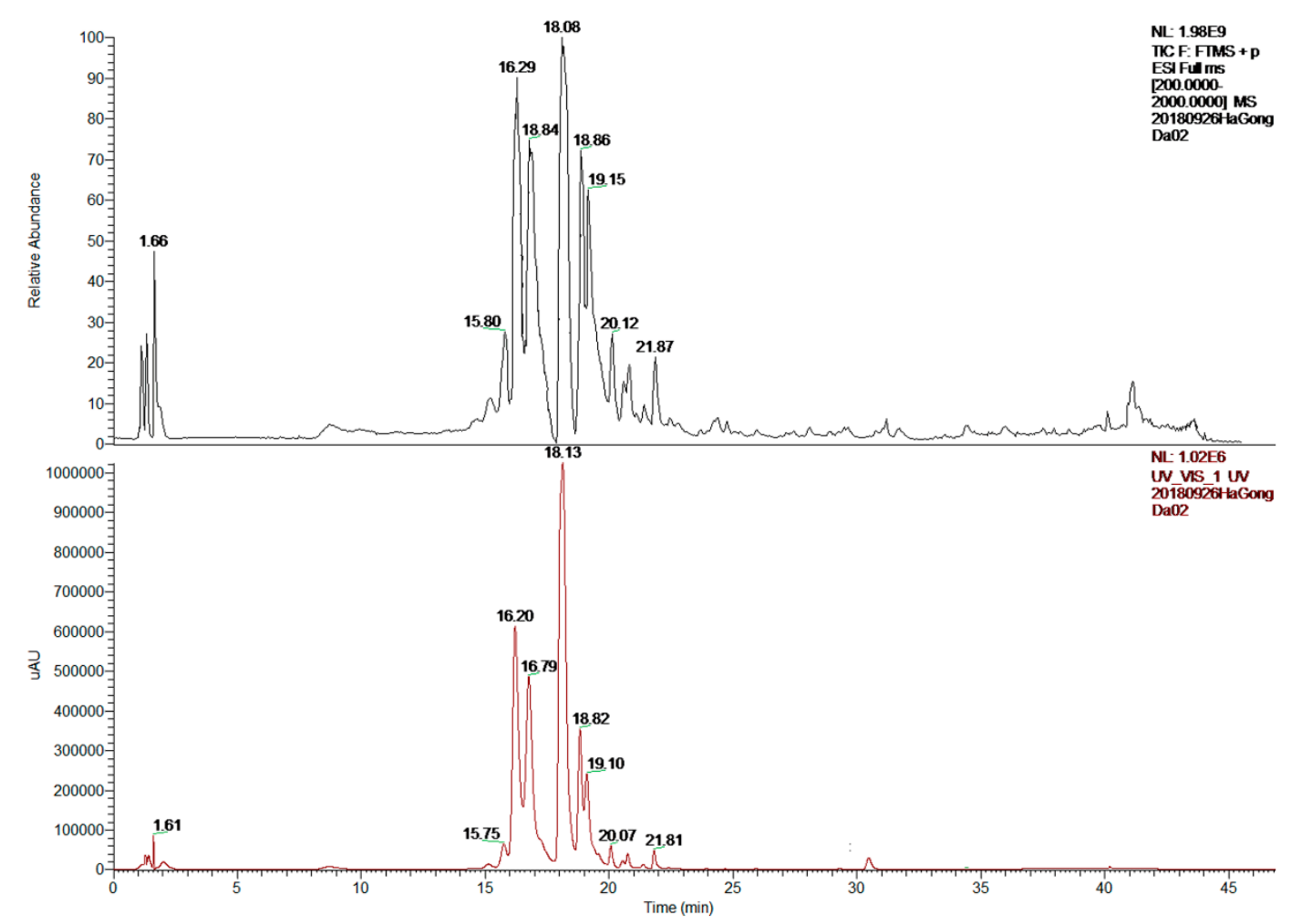

Figure 2. Total ion chromatogram and HPLC chromatogram of Fr3-3 by LC-MS/MS.

Table 2. Mass spectral data positive mode.

\begin{tabular}{|c|c|c|c|c|c|c|}
\hline Peak & RT (min) & MW & {$[\mathbf{M}+\mathbf{H}]^{+}(m / z)$} & $\operatorname{MS}^{2}(m / z)$ & $\begin{array}{l}\text { Molecular } \\
\text { Formula }\end{array}$ & Identification \\
\hline 1 & 15.80 & 594 & 595 & 431,147 & $\mathrm{C}_{30} \mathrm{H}_{26} \mathrm{O}_{13}$ & Kaempferol 3-(p-coumaryl) glucoside \\
\hline 3 & 16.84 & 594 & 595 & 433,271 & $\mathrm{C}_{27} \mathrm{H}_{30} \mathrm{O}_{15}$ & Apigenin $4^{\prime}, 7-O$-diglucoside \\
\hline 4 & 18.08 & 564 & 565 & $529,499,391$ & $\mathrm{C}_{26} \mathrm{H}_{28} \mathrm{O}_{14}$ & Schaftoside \\
\hline 5 & 18.86 & 564 & 565 & $547,511,427$ & $\mathrm{C}_{26} \mathrm{H}_{28} \mathrm{O}_{14}$ & Isoschaftoside \\
\hline 6 & 21.87 & 432 & 433 & $415,397,313,283$ & $\mathrm{C}_{21} \mathrm{H}_{20} \mathrm{O}_{10}$ & Apigenin $8-C-\alpha$-D-glucopyranoside \\
\hline
\end{tabular}

\subsection{Body Weight}

Figure 3 sketched these relationships between the body weight of mice and time during the 28 days of chronic restraint stress period. The body weight of the six groups showed an increasing trend with the prolonged feeding time, whereas mice in the CRS group had the slowest weight gain. The body weight in the CRS group was lower than that of other groups on the 8th day of administration. After 28 days of FSF and Flu administration, Flu $(10 \mathrm{mg} / \mathrm{kg})$ and different doses of FSF (35, 70 and $140 \mathrm{mg} / \mathrm{kg})$ could effectively alleviate the condition of slow weight gain $(p<0.05)$ compared with the CRS group. 


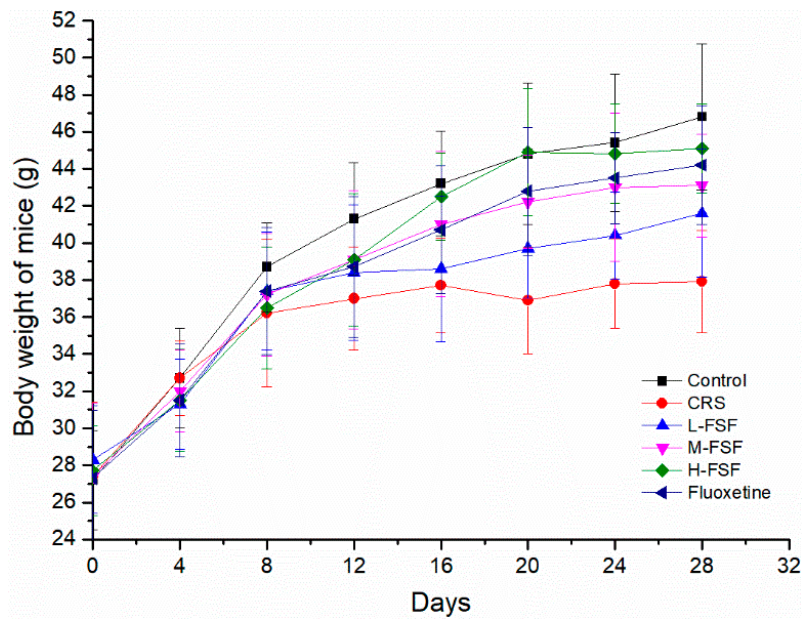

Figure 3. Body weight of mice during the period of chronic restraint stress, $\mathrm{n}=10$.

\subsection{Effects of FSF on Behavioral Tests}

As depicted in Figure 4, CRS increased immobility time in the forced swimming test and the tail suspension test, produced a depressant-like effect in the animals, and was significantly reduced in FSF and Flu treated mice $(p<0.05, p<0.01)$. After 28 days of the CRS procedure, sucrose preference was significantly reduced $(p<0.01)$. With the treatment of FSF and Flu during CRS, L-FSF $(35 \mathrm{mg} / \mathrm{kg})$ and M-FSF $(70 \mathrm{mg} / \mathrm{kg}$ ) treatment did not change the sucrose preference when compared with the CRS group, but H-FSF $(140 \mathrm{mg} / \mathrm{kg})$ and Flu $(10 \mathrm{mg} / \mathrm{kg})$ treatment significantly increased $(p<0.05)$, indicating that the H-FSF and Flu treatment could ameliorate depression-like behavior (Figure 4C). These results demonstrated the improved effect of FSF on depression-like behavior in CRS mice, similar to fluoxetine.

A
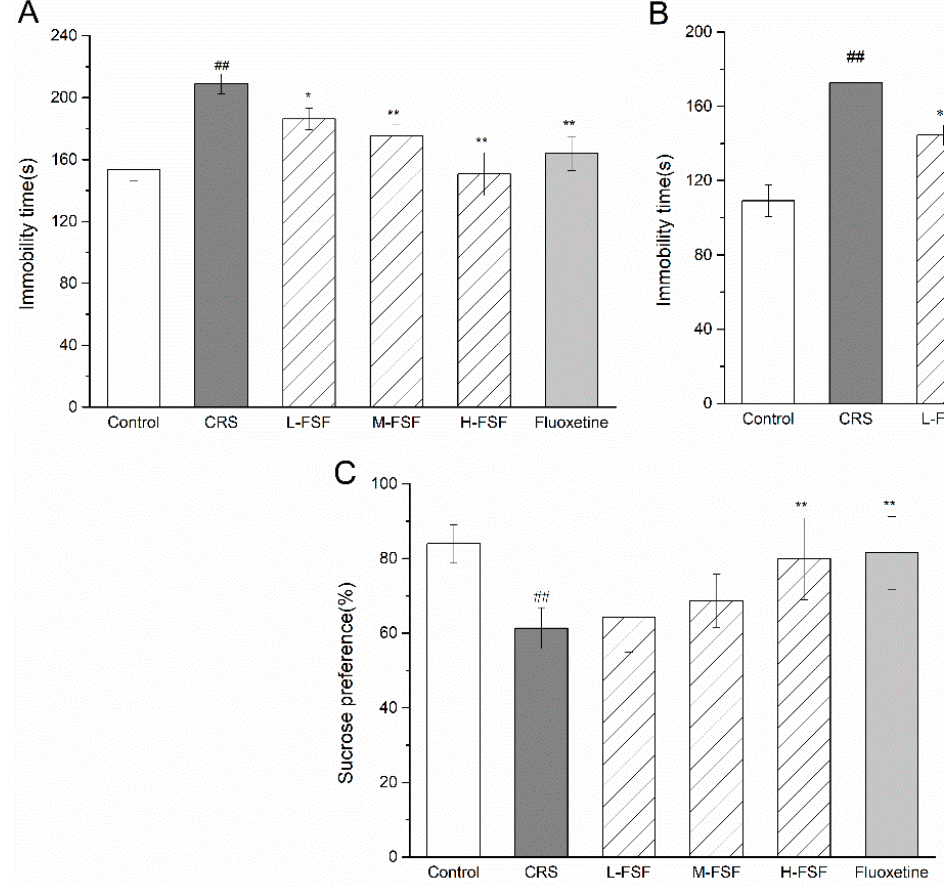

B

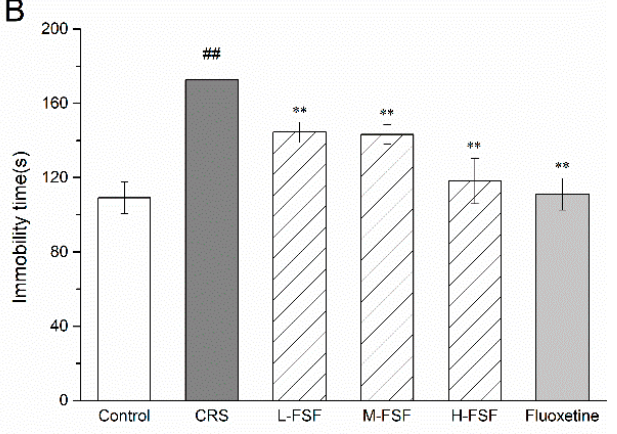

Figure 4. Effects of FSF on depressant-like behaviors in mice. (A) Forced swimming test. (B) Tail suspension test. (C) Sucrose preference test. $n=10,{ }^{\#} p<0.05,{ }^{\# \#} p<0.01$ vs. Control group; ${ }^{*} p<0.05$, ${ }^{* *} p<0.01$ vs. CRS treated group. 


\subsection{Effects of FSF on Organ Index}

The effect of FSF on organ index in mice is shown in Table 3. Thymus and spleen indices are to be closely bound up in an immune system, and the liver index is related to emotion. In fact, CRS remarkably diminished these indices $(p<0.05, p<0.01)$, whereas M-FSF $(70 \mathrm{mg} / \mathrm{kg})$ and H-FSF $(140 \mathrm{mg} / \mathrm{kg})$ significantly alleviated the reduction of liver and spleen indices $(p<0.05)$, respectively. FSF showed dose-dependent increase in thymus index. Similarly, the indices of liver, spleen and thymus were markedly restored $(p<0.05)$ after treatment with fluoxetine $(10 \mathrm{mg} / \mathrm{kg})$.

Table 3. Effects of FSF on the organ index in mice.

\begin{tabular}{cccc}
\hline Group & Liver Index $(\mathbf{m g} / \mathbf{g})$ & Spleen Index $(\mathbf{m g} / \mathbf{g})$ & Thymus Index $(\mathbf{m g} / \mathbf{g})$ \\
\hline Control & $56.33 \pm 4.39$ & $2.70 \pm 0.63$ & $2.66 \pm 0.82$ \\
CRS & $50.84 \pm 2.48^{\#}$ & $2.38 \pm 0.37^{\#}$ & $2.07 \pm 0.76^{\# \#}$ \\
L-FSF & $51.51 \pm 4.32$ & $2.50 \pm 0.25$ & $2.41 \pm 0.85^{*}$ \\
M-FSF & $56.33 \pm 4.39^{*}$ & $2.79 \pm 0.37^{*}$ & $2.40 \pm 0.79^{*}$ \\
H-FSF & $56.73 \pm 6.40^{*}$ & $2.79 \pm 0.25^{*}$ & $2.66 \pm 0.82^{* *}$ \\
Fluoxetine & $56.27 \pm 7.33^{*}$ & $2.87 \pm 0.61^{*}$ & $2.50 \pm 0.73^{*}$ \\
\hline \multicolumn{4}{r}{$n=10,{ }^{\#} p<0.05,{ }^{\# \#} p<0.01$, vs. Control group; ${ }^{*} p<0.05,{ }^{* *} p<0.01$, vs. CRS group. }
\end{tabular}

\subsection{Effects of FSF on Serum CORT Level}

The results of serum CORT level are presented in Figure 5. Compared with the control group, the serum CORT level of CRS mice increased significantly $(p<0.01)$, approximately $31 \%$. Significant decreases in serum CORT levels were observed in M-FSF $(p<0.01)$, H-FSF $(p<0.01)$ and Flu group $(p<0.05)$ severally. Unfortunately, there was no significant change in CORT levels in L-FSF. After FSF treatment, there was no significant difference compared with the normal CORT level $(p>0.05)$.

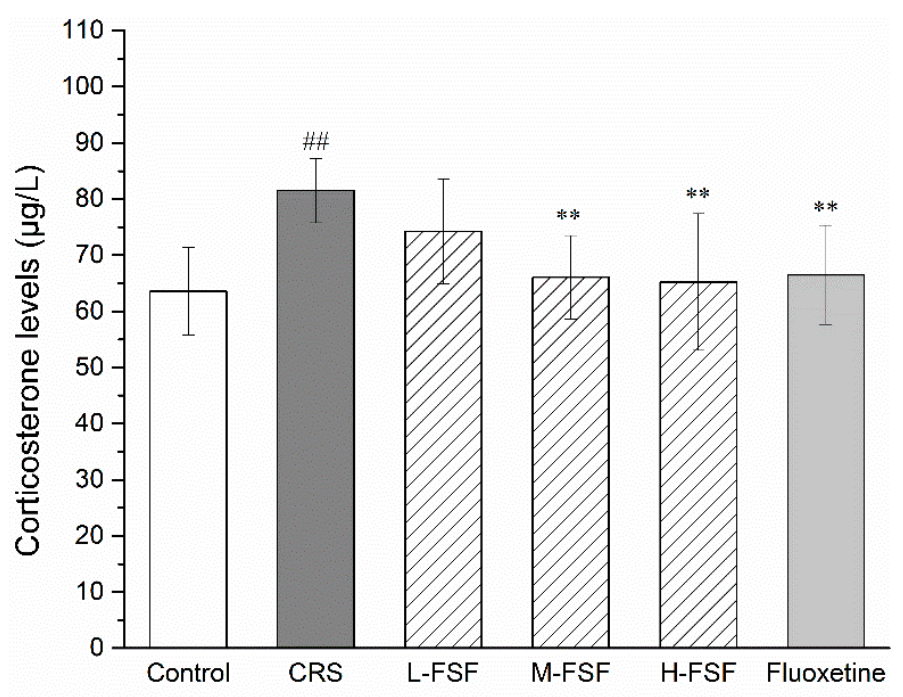

Figure 5. Effects of FSF on serum corticosterone level in mice. $n=10,{ }^{\# \#} p<0.01$, vs. Control group; ** $p<0.01$, vs. CRS group.

\subsection{Effects of FSF on NE Level in Different Brain Regions of Mice}

The levels of NE detected in the prefrontal cortex, hippocampus and striatum were summarized in Figure 6. Compared with the control group, the CRS group revealed a significant decrease in NE levels in both the prefrontal cortex $(p<0.05)$ and the hippocampus $(p<0.01)$. However, treatment with FSF increased NE levels in the prefrontal cortex, hippocampus and striatum $(p<0.05)$. Flu group also showed a significant increase of NE levels in three brain regions $(p<0.05)$. Additionally, there was no significant diversification in NE levels $(p>0.05)$ between the FSF and control groups. 


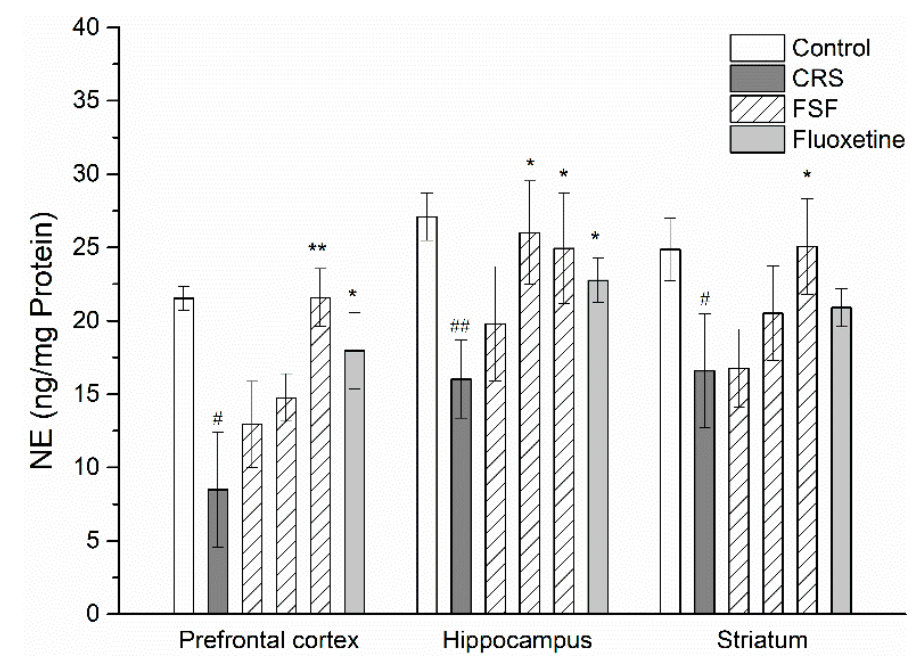

Figure 6. Effects of FSF on NE level in the prefrontal cortex, hippocampus and striatum in mice. $n=6$, ${ }^{\#} p<0.05,{ }^{\# \#} p<0.01$, vs. control group; ${ }^{*} p<0.05,{ }^{* *} p<0.01$, vs. CRS group.

\subsection{Effects of FSF on 5-HT and 5-HIAA Levels in Different Brain Regions of Mice}

Effects of CRS-induced stress on 5-HT and its metabolite (5-HIAA) levels in mice were depicted in Figure 7. The CRS induced a significant decrease in 5-HT levels $(p<0.05)$ and a significant increase in 5-HIAA levels $(p<0.05)$ in the both prefrontal cortex and hippocampus but not striatum, compared with the control group. Pretreatment with FSF reversed the decreased 5-HT levels induced by CRS $(p<0.05)$. The turnover rates of 5-HT dramatically increased $(p<0.05)$ in the prefrontal cortex and hippocampus. However, Flu did not have the same effect on the turnover rate of 5-HT (Figure 7C).

A

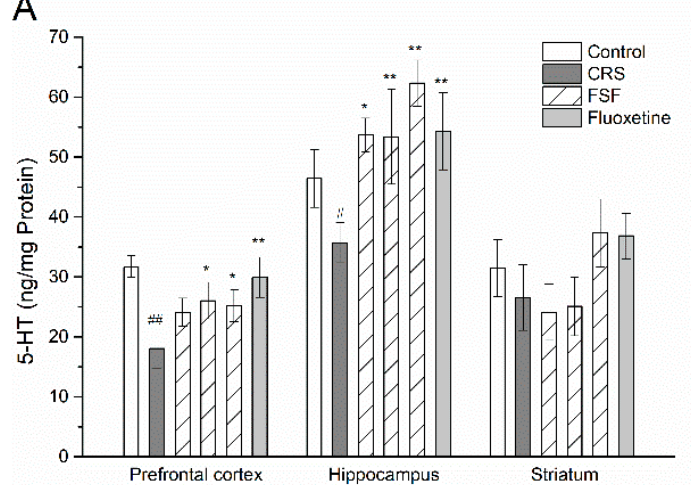

B

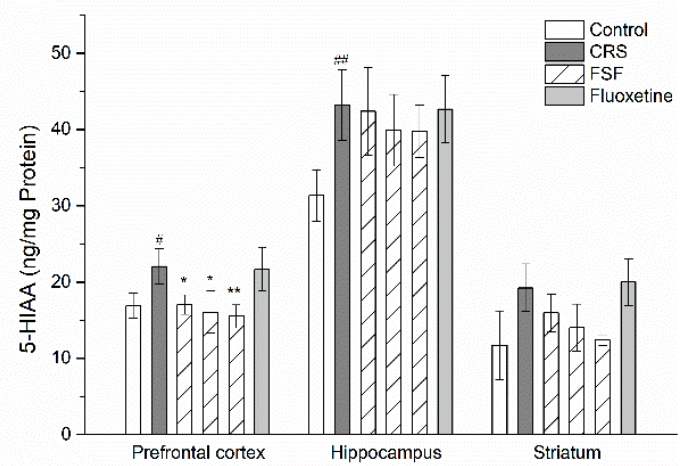

C

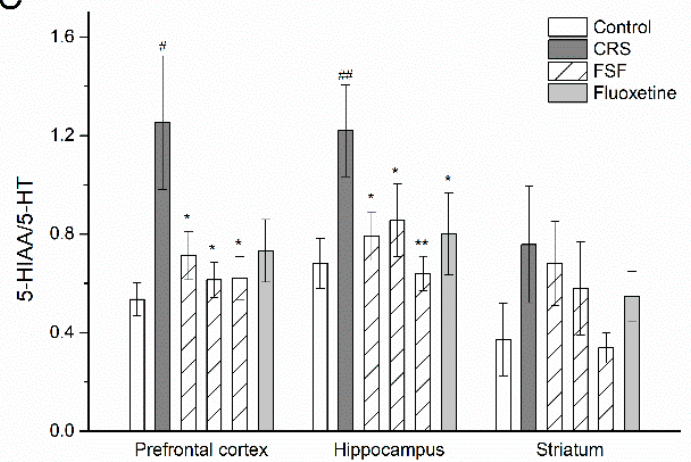

Figure 7. Effects of FSF on 5-HT and its metabolite levels in the prefrontal cortex, hippocampus and striatum in mice. (A) The level of 5-HT. (B) The level of 5-HIAA. (C) The rate of 5-HIAA/5-HT. $n=6$, ${ }^{\#} p<0.05,{ }^{\# \#} p<0.01$, vs. control group; ${ }^{*} p<0.05,{ }^{* *} p<0.01$, vs. CRS group. 


\subsection{Effects of FSF on DA, DOPAC, and HVA Levels in Different Brain Regions of Mice}

The effects of FSF and Flu on the DA and its metabolite (DOPAC and HVA) levels in the brains of mice exposed to the CRS were shown in Figure 8. After a period of four weeks stress administration, DA levels were drastically reduced in the prefrontal cortex $(p<0.05)$ and hippocampus $(p<0.01)$. Compared with the CRS group, FSF dose-dependently increased DA levels in the prefrontal cortex $(p<0.05, p<0.01)$; M-FSF (70 mg/kg), H-FSF (140 mg/kg) and Flu $(10 \mathrm{mg} / \mathrm{kg})$ showed an increase $(p<0.01)$ in DA in the hippocampus; but the DA levels did not show any significant effects in the striatum. Meanwhile, H-FSF and Flu could reverse the increase of DOPAC levels in the hippocampus induced by CRS. However, DOPAC levels showed no statistical difference in either the prefrontal cortex or the striatum. There was no significant difference in the HVA levels in the three brain regions. In addition, the turnover rate of DA in the prefrontal cortex and hippocampus in the CRS group increased $(p<0.05)$ compared to that in the control group (Figure 8D). However, supplementation of FSF contributed to decrease the turnover rates of DA in both the prefrontal cortex and hippocampus.
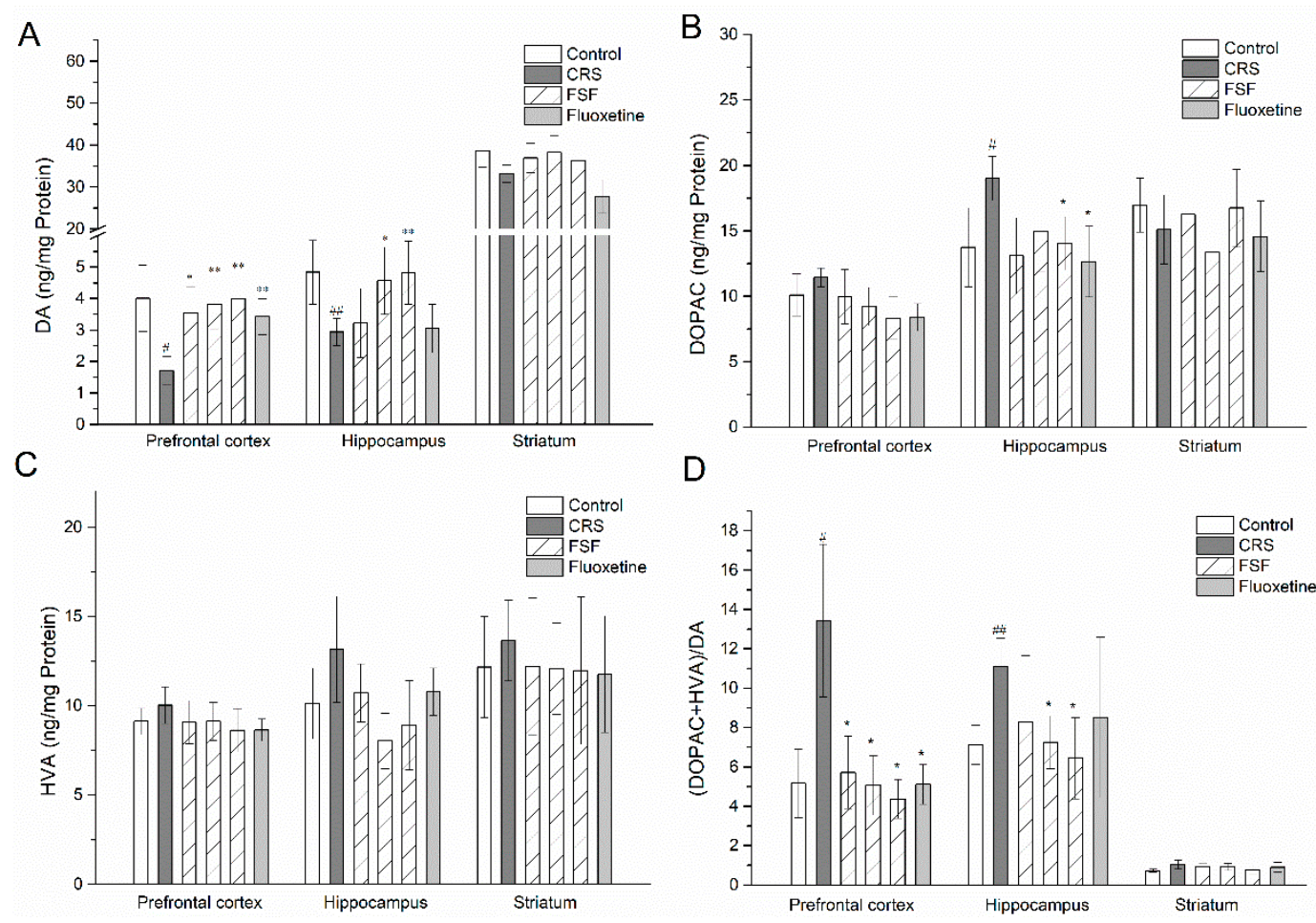

Figure 8. Effects of FSF on DA and its metabolites levels in the prefrontal cortex, hippocampus and striatum in mice. (A) The level of DA. (B) The level of DOPAC. (C) The level of HVA. (D) The rate of (DOPAC+HVA)/DA. $n=6,{ }^{\#} p<0.05,{ }^{\#} p<0.01$, vs. Control group; ${ }^{*} p<0.05,{ }^{* *} p<0.01$, vs. CRS group.

\subsection{Effects of FSF on MAO-A Activity in Different Brain Regions of Mice}

The activities of MAO-A detected in the prefrontal cortex, hippocampus and striatum were summarized in Figure 9. The MAO-A activity in the prefrontal cortex and hippocampus in CRS mice was increased significantly by about 1.5 -fold $(p<0.01)$ and 1.4 -fold $(p<0.01)$, compared with the control group. The MAO-A activity in the prefrontal cortex and hippocampus was significantly reduced by the supplementation of FSF in a dose dependent manner $(p<0.01)$. Meanwhile, with FSF treatment, the reduction of MAO-A activity is controllable, reducing to normal levels. In addition, fluoxetine had no meaningful effect on MAO-A activity in three brain regions. 


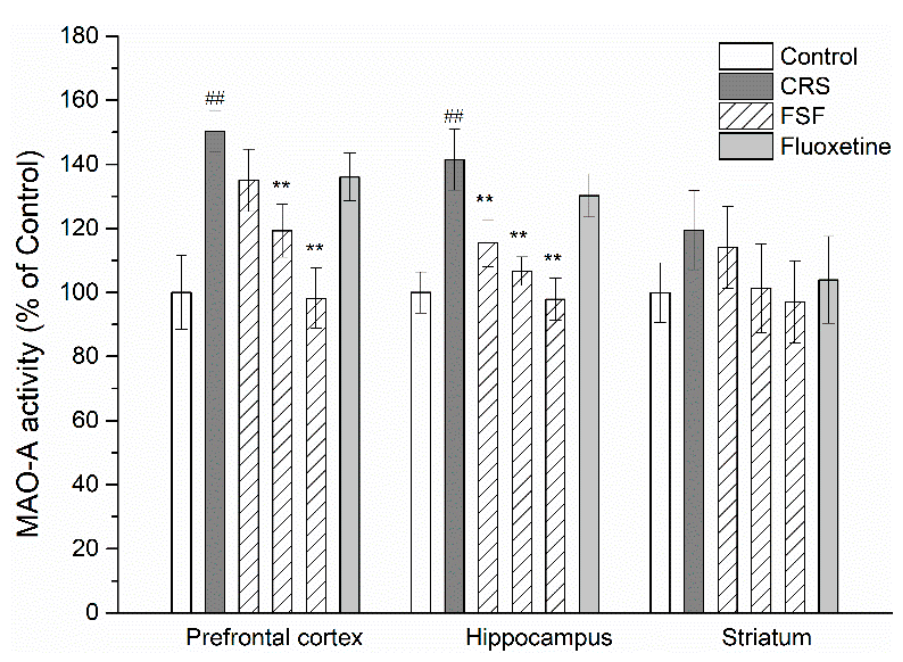

Figure 9. Effects of FSF on enzyme activities in the prefrontal cortex, hippocampus and striatum in mice. $n=6,{ }^{\# \#} p<0.01$, vs. control group; ${ }^{* *} p<0.01$, vs. CRS group.

\subsection{Effects of FSF on KLF11, SIRT1 and MAO-A Protein Level in Different Brain Regions of Mice}

The protein levels of KLF11, SIRT1 and MAO-A determined by western blot analysis were shown in Figure 10. In the prefrontal cortex, the results showed a significant increase $(p<0.01)$ in KLF11, SIRT1 and MAO-A protein expression between the Control and CRS groups. Meanwhile, there are similar results in the hippocampus. Compared with the CRS group, the protein levels decreased significantly $(p<0.05, p<0.01)$ after the FSF treatment in the prefrontal cortex and hippocampus, and there was a dependence on the FSF dose. However, there was no significant effect found with fluoxetine treatment on KLF11, SIRT1 and MAO-A protein expression in the prefrontal cortex and hippocampus.
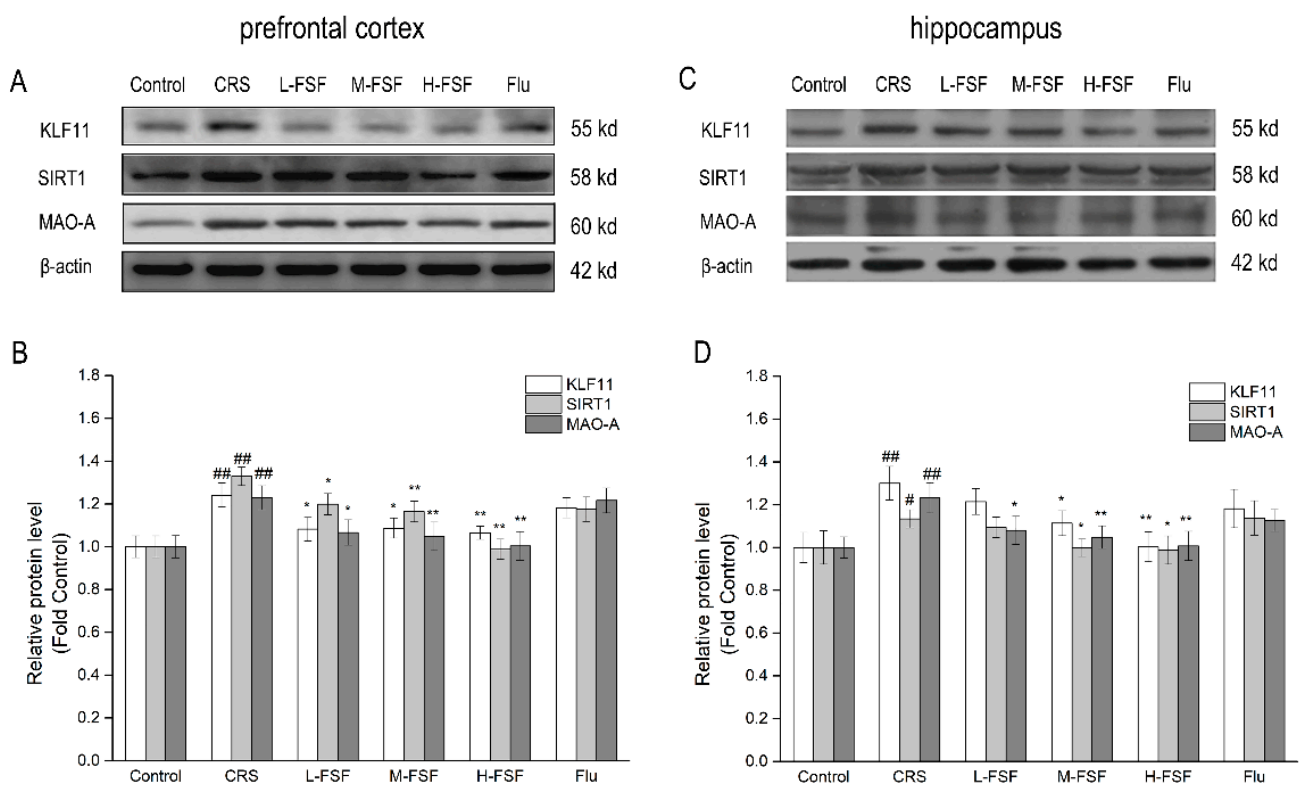

Figure 10. Effects of FSF on KLF11, SIRT1 and MAO-A protein level in the prefrontal cortex and hippocampus in mice. (A) Representative bands of protein in the prefrontal cortex. (B) The relative protein level in the prefrontal cortex. (C) Representative bands of protein in the hippocampus. (D) The relative protein level in the hippocampus. ${ }^{\#} p<0.05,{ }^{\#} p<0.01$, vs. control group; ${ }^{*} p<0.05,{ }^{* *} p<0.01$, vs. CRS group. 


\section{Discussion}

Stress can interfere with the nervous system, which is positively associated with the onset of depression $[37,38]$. Chronic restraint stress could produce persistent depressive-like symptoms in mice, which has been put forward as a widely used animal model of depression. The brain is the main target of stress-related psychiatric disorders $[39,40]$. In the present study, our studies establish that FSF exhibited the most effective MAO-A inhibition ability. Furthermore, the results demonstrate the KLF11/SIRT1-MAO-A signaling pathways and reveal the antidepressant-like effect of FSF mainly via modulation of monoamine regulatory pathways.

The decreased body weight after 28 days CRS exposure was shown in the present study. To a certain extent, weight loss could be used to assess the occurrence of depression. The extension of the immobility time in FST and TST can effectively reflect the behavioral despair and hopelessness, and sucrose preference is a behavioral indicator reflecting the degree of pleasure loss. In this study, we observed increased immobility in FST and TST as well as reduced sucrose preference after the CRS protocol, indicating that depression model was built successfully. Recent studies have also noted that CRS can induce depression-like behaviors in mice [41], which is in agreement with our results. The increased serum CORT level in CRS mice indicated that CRS could make the HPA axis hyperactive, and then lead to an imbalance of hormone levels in the body, particularly in the brain. However, treating mice with FSF and fluoxetine before the stressful events reversed the harmful change (reduced body weight and sucrose preference, increased immobility time and serum CORT levels in mice).

Previous studies have indicated that chronic stress could reduce monoamine transmitters (NE, 5-HT and DA) levels in the brain and induce depressive symptoms [42,43]. Since prefrontal cortex, hippocampus and striatum are associated with important functions such as mood, motivation, behavioral control, learning and memory [44], we chose these three brain regions for research. FSF has been proven to alleviate depressive-like symptoms and to increase the NE level in three brain regions. The levels of 5-HT and DA in the prefrontal cortex and hippocampus increased dramatically after FSF treatment, compared with the CRS group. Additionally, there was no significant diversification $(p>0.05)$ from the normal monoamine transmitters levels in the brain after FSF treatment. We detected that the turnover rate of 5-HT and DA decreased notably in the prefrontal cortex and hippocampus, which indicated a reduction in 5-HT and DA metabolism associated with MAO-A activity.

MAO-A participates in the metabolism of 5-HT, NE and DA, and brain MAO-A activity is positively correlated with depression [5]. To further address the molecular mechanism in regulation of neurotransmitter levels after FSF treatment, we measured the MAO-A activity in the three brain regions. We discovered that MAO-A activity was overactivated in the prefrontal cortex and hippocampus in the CRS group compared with the control group. However, there was no significant change in the striatum. With the treatment of FSF, the MAO-A activity was inhibited. However, fluoxetine had no effect on MAO-A activity. Results from several studies have identified that the severity of depressive symptoms is associated with reduced MAO-A activity and increased neurotransmitter levels [5,9,45].

KLF11 and SIRT1 are the key transcriptional up-regulators of MAO-A. KLF11 directly regulates MAO-A gene transcription, and SIRT1 indirectly regulates MAO-A gene transcription through deacetylase and activation of NHLH2 and FOXO1 [11,46]. Our studies showed that the CRS group displayed an increase in protein expression of KLF11, SIRT1 and MAO-A compared with the control group, indicating that the KLF11-MAO-A and SIRT1-MAO-A pathways were overactivated by CRS exposure. FSF could inhibit MAO-A activity and reduce the expression of KLF11 and SIRT1 proteins, thereby decrease MAO-A protein level. The result is consistent with the report that MAO-A inhibitors treatment during chronic stress exposure downregulates the KLF11-MAO-A and SIRT1-MAO-A pathways $[46,47]$. However, fluoxetine has no significant effect on KLF11, SIRT1 and MAO-A protein expression in the prefrontal cortex and hippocampus, which suggested that fluoxetine did not participate in this pathway for antidepressant effects. Fluoxetine selectively inhibits 5-HT transporters, blocks pre-synaptic membrane reuptake of 5-HT, prolongs and increases 5-HT action, resulting in antidepressant effects. 


\section{Materials and Methods}

\subsection{Chemicals and Drugs}

Gynostemma pentaphyllum, Trigonella foenum-graecum seeds, Polygala tenuifolia, Ginkgo biloba leaves, Astragalus membranaceus, Radix paeoniae alba and Suanzaorenhehuan were purchased from Harbin Xinheng Traditional Chinese Medicine Materials Ltd. (Harbin, China) and authenticated by Professor Lianjie Su, Heilongjiang University of Chinese Medicine. HP-20 macroporous resin and Sephadex LH-20 were obtained from Soledad Technology Co., Ltd. (Beijing, China). Clorgiline, pargilin, fluoxetine (Flu) were purchased from Sigma (St. Louis, MO, USA). Casein, vanilla acid, 4-aminoantipyrine and horseradish peroxidase were purchased from Aladdin Bio-Chem Technology Co., Ltd. (Shanghai, China).

\subsection{Extraction and Isolation}

All plants were extracted with $60 \%(v / v)$ ethanol, under sonication for $60 \mathrm{~min}$ at $50{ }^{\circ} \mathrm{C}$ for two times and filtered and evaporated at $45^{\circ} \mathrm{C}$. Then MAO-A inhibition activity of each extract was evaluated, and the ethanol extract of Trigonella foenum-graecum seeds showed the most significant inhibition. The extract was separated and purified by HP-20 macroporous resin eluted with water, 10\%, $30 \%, 50 \%, 70 \%, 90 \%$ ethanol. The eluted fractions (Fr 1, Fr 2, Fr 3, Fr 4, Fr 5, Fr 6) were concentrated and dried. The MAO-A inhibition activity was investigated, and the Fr 3 showed the most significant inhibition. To further identify Fr 3, we adopted Sephadex LH-20 to analyze the active fractions in Fr 3 by using methanol and water (30:70), and obtained three fractions (Fr 3-1, Fr 3-2, Fr 3-3). Each fraction was evaluated for MAO-A inhibition again, and the results showed that the Fr 3-3 exhibit the most significant inhibition. Then Fr 3-3 was obtained and stored at $4{ }^{\circ} \mathrm{C}$ for the next experiments.

\subsection{Screening for $M A O-A$ Inhibitors In Vitro}

Extraction and preparation of MAO refer to previous methods [48]. The crude enzyme solution was diluted 4 times, and the corresponding volume of $500 \mathrm{nmol} / \mathrm{L}$ pargilin solution (a selective MAO-B inhibitor) was pre-incubated for $30 \mathrm{~min}$ to completely inhibit MAO-B, and the MAO-A working solution was prepared [49]. Then, $40 \mu \mathrm{L}$ enzyme and $40 \mu \mathrm{L}$ sample solution of different concentrations were added to the 96-well plate. After incubation at $37^{\circ} \mathrm{C}$, add $120 \mu \mathrm{L}$ substrate was immediately added $(2.5 \mathrm{mmol} / \mathrm{L}$ casein, prepared from $0.2 \mathrm{~mol} / \mathrm{L} \mathrm{PH} 7.6 \mathrm{PBS})$, as was $40 \mu \mathrm{L}$ developing solution ( $1 \mathrm{mmol} / \mathrm{L}$ vanilla acid, $0.5 \mathrm{mmol} / \mathrm{L} 4$-aminoantipyrine, $4 \mathrm{U} / \mathrm{mL}$ horseradish peroxidase, by $0.2 \mathrm{~mol} / \mathrm{L} \mathrm{PH} 7.6$ of PBS). After incubation at $37^{\circ} \mathrm{C}$, the absorbance value of $490 \mathrm{~nm}$ was determined by using a multifunctional enzyme marker (Varioskan Flash, Thermo Fisher Scientific, Waltham, MA, USA).

\subsection{LC-MS/MS Analysis}

The Fr3-3 was analyzed by using LC-MS/MS (APEX IV, FT-MS, Bruker, USA) equipped with Extend-C18 column $(1.8 \mu \mathrm{m}, 2.1 \times 50 \mathrm{~mm})$ with UV detection at $280 \mathrm{~nm}$. Acetonitrile (A) and acidified water (B, 0.1\% formic acid, v/v) were elution solvent. Elution program: 0-20 min (5-25\% A), 20-30 min (25-40\% A), 30-40 min (40-70\% A), 40-60 min (70-100\% A). The column temperature was $30{ }^{\circ} \mathrm{C}$, the flow rate was $0.5 \mathrm{~mL} / \mathrm{min}$, and the sample loading was $10 \mu \mathrm{L}$. Major parameters: spray voltage, $3000 \mathrm{~V}$; evaporator temperature, $300^{\circ} \mathrm{C}$; sheath gas $\left(\mathrm{N}_{2}\right)$ pressure, 4.0 bar; and scan range, $m / z 150-1000$. The collision energy was initially set at $10 \mathrm{eV}$ for the MS/MS experiments of the preferred ions and then modified according to the fragments.

\subsection{Animals and Experimental Design}

Male KM mice (18-22 g) were purchased from the Animal Center of Harbin Medical University (SCXK(Hei)2006-008). All experimental procedures were approved by the Animal Research Committee 
of Harbin Medical University. The animals were housed in cages $\left(23 \pm 2{ }^{\circ} \mathrm{C}, 12\right.$-h light and 12 -h dark periods) with ad libitum access to food and water. After 7 days of adaptive feeding, animals were randomly separated into the following 6 experimental groups (10 mice per group): Control group, Chronic Restraint Stress group (CRS), Fluoxetine group (Flu, $10 \mathrm{mg} / \mathrm{kg}$, p.o., as positive group), L-FSF group (35 mg/kg, p.o.), M-FSF (70 mg/kg, p.o.) and H-FSF (140 mg $/ \mathrm{kg}$, p.o.). Control group was given equal volume of distilled water. In addition to the control group, the remaining five groups were exposed to CRS for 28 days.

\subsection{Chronic Restraint Stress Protocol}

The CRS was performed by adapting the procedure used by Shuichi et al. [50]. Restraint stress was applied $4 \mathrm{~h} / \mathrm{d}$ between 9 A.M. and 1 P.M. for $28 \mathrm{~d}$ with acrylic cylinder (inner diameter $6.5 \mathrm{~cm}$, length $20.0 \mathrm{~cm}$, vent hole at the end of the cylinder) that can effectively immobilize the mice. After $4 \mathrm{~h}$ of restraint stress, the mice ad libitum accessed food and water.

\subsection{Behavioral Tests}

\subsubsection{Forced Swimming Test}

A forced swimming test was performed with some previously reported methods and several modifications were made [51]. The mice were placed in a glass $(25 \mathrm{~cm}$ high $\times 15 \mathrm{~cm}$ diameter) containing $25 \mathrm{~cm}$ of water $\left(25 \pm 1^{\circ} \mathrm{C}\right)$. On the first day, the mice were placed in a glass for $15 \mathrm{~min}$ to induce a helpless state, and then they were returned to the glass for $6 \mathrm{~min}$ on the second day, and the immobility time was finally measured over $4 \mathrm{~min}$. Immobility was defined as the action required to keep the heads of all the mice above the water surface without all movements.

\subsubsection{Tail Suspension Test}

Tail suspension test was implemented according to a previously reported method [52]. The mice tails were fixed on the top of the soundproof box with medical tape, and the heads were $20 \mathrm{~cm}$ from the floor. The mice were suspended for $6 \mathrm{~min}$ and the immobility time was measured at last $4 \mathrm{~min}$. Immobility time was defined as the lack of escape-oriented behavior. Moreover, when mice did not have any physical movement, they were considered to be passively hanging and not moving at all.

\subsubsection{Sucrose Preference Test}

Sucrose preference test was performed according to a previously described method [53], with some modifications. Twenty-four hours prior to testing, mice were not allowed to drink water. After that the mice were given two bottles of water and $1 \%$ sucrose solution at the same time. In order to determine the sucrose preference in mice, the weight of each bottle was weighed and the amount of solution consumed was calculated after $24 \mathrm{~h}$.

\subsection{Blood and Tissue Sample Collection}

The blood samples were collected by removing eyeball and kept at room temperature for $1 \mathrm{~h}$, centrifuged at $3000 \mathrm{rpm}$ for $20 \mathrm{~min}$ to obtain serum, and stored at $-80{ }^{\circ} \mathrm{C}$ for the subsequent corticosterone assays. The mice were decapitated and the brains were quickly removed on ice. The prefrontal cortex, hippocampus and striatum were isolated according to the reported protocol [54], and were stored at $-80^{\circ} \mathrm{C}$. The prefrontal cortex, hippocampus and striatum were homogenized with cold phosphate buffer ( $\mathrm{pH} 7.4,0.05 \mathrm{M}, 1: 10 \mathrm{w} / \mathrm{v})$ using a Teflon-glass homogenizer.

\subsection{Determination of CORT, Monoamines and Its Metabolites}

The levels of serum CORT and monoamine neurotransmitters (NE, 5-HT, 5-HIAA, DA, DOPAC and HVA) were measured using commercial ELISA kits (Mercker Biological Technology Co., Ltd., Wuhan, China) according to the manufacturer's instructions. The absorbance was measured at 
$450 \mathrm{~nm}$ using a microplate reader (Multiskan Spectrum, Thermo Fisher Scientific, USA) within 15 min. Protein concentrations were estimated by the BCA method using a BSA protein analysis kit (Nanjing Bioengineering Institute, Nanjing, China).

\subsection{Measurements of MAO-A Activity}

The MAO-A activity was performed using a previously reported method [9], with some modification. Brain tissue homogenates were then centrifuged at $3000 \mathrm{rpm}$ for $5 \mathrm{~min}$ at $4{ }^{\circ} \mathrm{C}$ twice. The supernatant was transferred to a new tube and centrifuged at $12,000 \mathrm{rpm}$ for $10 \mathrm{~min}$ at $4{ }^{\circ} \mathrm{C}$. The pellets were resuspended in the same buffer. The MAO-A activity was measured using a MAO-Glo ${ }^{\mathrm{TM}}$ kit (Promega, WI, USA) according to the manufacturer's instructions. The data were measured by using a multifunctional enzyme marker (Varioskan Flash, Thermo Fisher Scientific, USA). Protein concentrations were estimated by the BCA method using a BSA protein analysis kit (Nanjing Jiancheng Bioengineering Institute, Nanjing, China).

\subsection{Western Blot Analysis}

The prefrontal cortex and hippocampus were homogenized in a RIPA buffer. Lysates were centrifuged at $4{ }^{\circ} \mathrm{C}, 12,000 \mathrm{rpm}$ for $10 \mathrm{~min}$, and the supernatant was obtained and stored at $-20{ }^{\circ} \mathrm{C}$. Protein concentrations were estimated by the BCA method using BSA protein analysis kit. Twenty micrograms of total protein from each sample were separated in 10.5\% SDS-PAGE gel by electrophoresis and transferred onto a PVDF membrane. The membrane was blocked with $5 \%$ non-fat dry milk for $1 \mathrm{~h}$ at room temperature and incubated with rabbit anti-MAO-A antibody, rabbit anti-KLF11 antibody and rabbit anti-SIRT1 antibody (1:1000; bs-6679R, bs-16096R, bs-0921R; Biosynthesis Biotechnology, China) for $1 \mathrm{~h}$ at room temperature. Then, the membrane was incubated with horseradish peroxidase-conjugated secondary antibodies for $2 \mathrm{~h}$ at room temperature to visualize blots. $\beta$-Actin was used as an internal reference protein.

\subsection{Data Analysis}

Data were expressed as mean \pm SEM and analyzed by one-way ANOVA, and then Tukey test and Dunnet's multiple comparisons were performed using SPSS version 16.0 statistical software (IBM, New York, NY, USA). Differences in $p<0.05$ were considered significant in all tests.

\section{Conclusions}

In summary, the present study revealed the antidepressant effect of flavonoids from Trigonella Foenum-Graecum seeds that could inhibit the expression and activity of MAO-A by down-regulating the KLF11-MAO-A and SIRT1-MAO-A signal pathways, and by regulating the levels of monoamine neurotransmitters (NE, 5-HT, DA and their metabolites) in the prefrontal cortex, hippocampus and striatum in chronic restraint stress mice. Further research in animal studies is needed to better understand the potential impacts of these findings.

Supplementary Materials: The following are available online. Figure S1: The mass spectra and chemical structures of compounds of FSF.

Author Contributions: Conceptualization, C.C. and Z.W.; Formal analysis, J.W. and C.X.; Investigation, J.W. and C.C.; Methodology, J.W., C.C. and C.X.; Writing-original draft, J.W.; Writing-review\&editing, C.C. and Z.W. Authorship must be limited to those who have contributed substantially to the work reported.

Funding: This research was supported by the National Key R\&D Program of China (2017YFD0400505) and the National Key Research and Development Program of China under Grant (2016YFC0500305).

Acknowledgments: Thanks to the technical support provided by the Biosynthesis and Separation Laboratory of Harbin Institute of Technology.

Conflicts of Interest: The authors declare no conflict of interest. 


\section{References}

1. Lépine, J.P.; Briley, M. The increasing burden of depression. Neuropsychiatr. Dis. Treat. 2011, 2011, 3-7.

2. Thakare, V.N.; Dhakane, V.D.; Patel, B.M. Potential antidepressant-like activity of silymarin in the acute restraint stress in mice: Modulation of corticosterone and oxidative stress response in cerebral cortex and hippocampus. Pharmacol. Rep. 2016, 68, 1020-1027. [CrossRef] [PubMed]

3. Frank, E.; Prien, R.F.; Jarrett, R.B.; Keller, M.B.; Kupfer, D.J.; Lavori, P.W.; Rush, A.J.; Weissman, M.M. Conceptualization and rationale for consensus definitions of terms in major depressive disorder. Remission, recovery, relapse, and recurrence. Arch. Gen. Psychiatry 1991, 48, 851-855. [CrossRef] [PubMed]

4. Xu, Y.; Zhang, C.; Wu, F.; Xu, X.; Wang, G.; Lin, M.; Yu, Y.; Pan, J. Piperine potentiates the effects of trans -resveratrol on stress-induced depressive-like behavior: involvement of monoaminergic system and cAMP-dependent pathway. Metab. Brain Dis. 2016, 31, 837-848. [CrossRef]

5. Naoi, M.; Maruyama, W.; Shamoto-Nagai, M. Type A monoamine oxidase and serotonin are coordinately involved in depressive disorders: from neurotransmitter imbalance to impaired neurogenesis. J. Neural Transm. 2018, 125, 53-66. [CrossRef]

6. Liu, L.; Zhou, X.; Zhang, Y.; Liu, Y.; Yang, L.; Pu, J.; Zhu, D.; Zhou, C.; Xie, P. The identification of metabolic disturbances in the prefrontal cortex of the chronic restraint stress rat model of depression. Behav. Brain Res. 2016, 305, 148-156. [CrossRef]

7. Higuchi, Y.; Soga, T.; Parhar, I.S. Regulatory Pathways of Monoamine Oxidase A during Social Stress. Front. Neurosci. 2017, 11, 604. [CrossRef]

8. Kochanowska, K.J.A.; Hamann, T.M. Marine indole alkaloids: potential new drug leads for the control of depression and anxiety. Chem. Rev. 2010, 110, 4489-4497. [CrossRef]

9. Garcia, M.; Ooi, J.; Bardile, C.F.; Liang, J.T.; George, M.; Drum, C.L.; Lin, R.Y.; Hayden, M.R.; Pouladi, M.A. Treatment with the MAO-A inhibitor clorgyline elevates monoamine neurotransmitter levels and improves affective phenotypes in a mouse model of Huntington disease. Exp. Neurol. 2016, 278, 4-10. [CrossRef]

10. Chinelo, U.; Shakevia, J.; Stockmeier, C.A.; Jia, L.; Albert, P.R.; Junming, W.; May, W.L.; Grazyna, R.; Sharonda, H.; Sittman, D.B. The expression of KLF11 (TIEG2), a monoamine oxidase B transcriptional activator in the prefrontal cortex of human alcohol dependence. Alcohol. Clin. Exp. Res. 2014, 38, 144-151.

11. Matthew, G.; Shakevia, J.; Deyin, L.; Zhe, W.; Gwen, L.; Albert, P.R.; Stockmeier, C.A.; Meyer, J.H.; Raul, U.; Miczek, K.A. Mechanistic role for a novel glucocorticoid-KLF11 (TIEG2) protein pathway in stress-induced monoamine oxidase A expression. J. Biol. Chem. 2012, 287, 24195-24206.

12. Duncan, J.; Wang, N.; Zhang, X.; Johnson, S.; Harris, S.; Zheng, B.; Zhang, Q.; Rajkowska, G.; Miguel-Hidalgo, J.J.; Sittman, D. Chronic Social Stress and Ethanol Increase Expression of KLF11, a Cell Death Mediator, in Rat Brain. Neurotox. Res. 2015, 28, 1-14. [CrossRef]

13. Libert, S.; Pointer, K.; Bell, E.; Das, A.; Cohen, D.; Asara, J.; Kapur, K.; Bergmann, S.; Preisig, M.; Otowa, T. SIRT1 Activates MAO-A in the Brain to Mediate Anxiety and Exploratory Drive. Cell 2011, 147, 1459-1472. [CrossRef]

14. Cai, N.; Bigdeli, T.B.; Kretzschmar, W.; Li, Y.; Liang, J.; Song, L.; Hu, J.; Li, Q.; Jin, W.; Hu, Z. Sparse whole-genome sequencing identifies two loci for major depressive disorder. Nature 2015, 523, 588-591. [CrossRef]

15. Karson, A.; Demirtaş, T.; Bayramgürler, D.; Balci, F.; Utkan, T. Chronic Administration of Infliximab (TNF-Alpha Inhibitor) Decreases Depression and Anxiety-like Behaviour in Rat Model of Chronic Mild Stress. Basic Clin. Pharmacol. Toxicol. 2013, 112, 335-340. [CrossRef]

16. Willner, P.; Muscat, R.; Papp, M. Chronic mild stress-induced anhedonia: A realistic animal model of depression. Neurosci. Biobehav. Rev. 1992, 16, 525-534. [CrossRef]

17. Liang, S.; Wang, T.; Hu, X.; Luo, J.; Li, W.; Wu, X.; Duan, Y.; Jin, F. Administration of Lactobacillus helveticus NS8 improves behavioral, cognitive, and biochemical aberrations caused by chronic restraint stress. Neuroscience 2015, 310, 561-577. [CrossRef]

18. Lin, Y.E.; Lin, S.H.; Chen, W.C.; Ho, C.T.; Lai, Y.S.; Panyod, S.; Sheen, L.Y. Antidepressant-like effects of water extract of Gastrodia elata Blume in rats exposed to unpredictable chronic mild stress via modulation of monoamine regulatory pathways. J. Ethnopharmacol. 2016, 187, 57-65. [CrossRef] 
19. Akter, S.; Sasaki, H.; Uddin, K.R.; Ikeda, Y.; Miyakawa, H.; Shibata, S. Anxiolytic effects of gamma-oryzanol in chronically- stressed mice are related to monoamine levels in the brain. Life Sci. 2019, 216, 119-128. [CrossRef]

20. Khan, H.; Perviz, S.; Sureda, A.; Nabavi, S.M.; Tejada, S. Current standing of plant derived flavonoids as an antidepressant. Food Chem. Toxicol. 2018, 119, 176-188. [CrossRef]

21. Orhan, I.E. Potential of Natural Products of Herbal Origin as Monoamine Oxidase Inhibitors. Curr. Pharm. Des. 2016, 22, 268-276. [CrossRef]

22. Carradori, S.; Gidaro, M.C.; Petzer, A.; Costa, G.; Guglielmi, P.; Chimenti, P.; Alcaro, S.; Petzer, J.P. Inhibition of Human Monoamine Oxidase: Biological and Molecular Modeling Studies on Selected Natural Flavonoids. J. Agric. Food Chem. 2017, 64, 9004-9011. [CrossRef]

23. Abushouk, A.I.; Negida, A.; Ahmed, H.; Abdel-Daim, M.M. Neuroprotective mechanisms of plant extracts against MPTP induced neurotoxicity: Future applications in Parkinson's disease. Biomed. Pharmacother. 2017, 85, 635-645. [CrossRef]

24. Jiger, A.K.; Bente, G.; Jacob, A.; Anne, A.; Lene, G. Screening of plants used in Danish folk medicine to treat depression and anxiety for affinity to the serotonin transporter and inhibition of MAO-A. J. Ethnopharmacol. 2013, 145, 822-825. [CrossRef]

25. Yuan, H.; Ming, L.; Ping, L.; Dai-Hong, G.; Ri-Bao, W.; Khalid, R. Possible mechanism of the antidepressant effect of 3,6'-disinapoyl sucrose from Polygala tenuifolia Willd. J. Pharm. Pharmacol. 2011, 63, 869-874.

26. Sloley, B.; Urichuk P, L.; Durkin, J.; Shan, J.; Pang, P.; Coutts, R. Identification of kaempferol as a monoamine oxidase inhibitor and potential Neuroprotectant in extracts of Ginkgo biloba leaves. J. Pharm. Pharmacol. 2010, 52, 451-459. [CrossRef]

27. Alsnafi, A. Detoxification capacity and protective effects of medicinal plants (part 2): plant based review. IOSR J. Pharm. 2016, 6, 63-84.

28. Liu, J.; Qiao, W.; Yang, Y.; Ren, L.; Sun, Y.; Wang, S. Antidepressant-like effect of the ethanolic extract from Suanzaorenhehuan Formula in mice models of depression. J. Ethnopharmacol. 2012, 141, 257-264. [CrossRef]

29. Liang, Y.; Yang, X.; Zhang, X.; Duan, H.; Jin, M.; Sun, Y.; Yuan, H.; Li, J.; Qi, Y.; Qiao, W. Antidepressant-like effect of the saponins part of ethanol extract from SHF. J. Ethnopharmacol. 2016, 191, 307-314. [CrossRef]

30. Sarrisab, J.; Schweitzer, I.; Stough, C.; Scholey, A. Herbal medicine for depression, anxiety and insomnia: A review of psychopharmacology and clinical evidence. Eur. Neuropsychopharmacol. J. Eur. Coll. Neuropsychopharmacol. 2011, 21, 841-860. [CrossRef]

31. Li, P.; Dai, W.; Lu, M.; Xie, D.; Tan, J.; Yang, C.; Zhu, Y.; Lv, H.; Peng, Q.; Zhang, Y. Metabolomic analysis reveals the composition differences in 13 Chinese tea cultivars of different manufacturing suitabilities. J. Sci. Food Agric. 2018, 98, 1153-1161. [CrossRef]

32. Mohamed, G.A. Alliuocide $\mathrm{G}$, a new flavonoid with potent alpha-amylase inhibitory activity from Allium cepa L. Arkivoc 2008, 2008, 202-209.

33. Stobiecki, M.; Kachlicki, P.; Wojakowska, A.; Marczak, Ł. Application of LC/MS systems to structural characterization of flavonoid glycoconjugates 추. Phytochem. Lett. 2015, 11, 358-367. [CrossRef]

34. Pan, S.K.; Ji, H.S.; Jo, D.S.; Dong, W.S.; Choi, D.H.; Kim, W.J.; Park, K.; Jin, K.K.; Joo, C.G.; Lee, J.S. Anti-melanogenic activity of schaftoside in Rhizoma Arisaematis by increasing autophagy in B16F1 cells. Biochem. Biophys. Res. Commun. 2018, 503, 309-315.

35. Shan, D.S.; Ming, Z.H.; Chun Qi, B.; Fang, W.C.; Zhi, L.Q.; Long, L.Z.; Yan, W.Y.; Wei, D.Z. Nematocidal flavone-C-glycosides against the root-knot nematode (Meloidogyne incognita) from Arisaema erubescens tubers. Molecules 2011, 16, 5079-5086.

36. Laitonjam, W. Study on Isolation and Comparison of the Chemical Compositions of Cissus adnata Roxb. leaves and Smilax lanceaefolia Roxb. Roots and Their Free Radical Scavenging Activities. Int. Res. J. Pure Appl. Chem. 2011, 1. [CrossRef]

37. Kioukia, F.N.; Antoniou, K.; Bekris, S.; Liapi, C.; Christofidis, I.; Papadopoulou-Daifoti, Z. The effects of stress exposure on the hypothalamic-pituitary-adrenal axis, thymus, thyroid hormones and glucose levels. Prog. Neuropsychopharmacol. Biol. Psychiatry 2002, 26, 823-830. [CrossRef]

38. Xu, P.; Wang, K.; Lu, C.; Dong, L.; Chen, Y.; Wang, Q.; Shi, Z.; Yang, Y.; Chen, S.; Liu, X. Effects of the chronic restraint stress induced depression on reward-related learning in rats. Behav. Brain Res. 2017, 321, 185-192. [CrossRef] 
39. Gregus, A.; Wintink, A.J.; Davis, A.C.; Kalynchuk, L.E. Effect of repeated corticosterone injections and restraint stress on anxiety and depression-like behavior in male rats. Behav. Brain Res. 2005, 156, 105-114. [CrossRef]

40. Fogaça, M.V.; Campos, A.C.; Coelho, L.D.; Duman, R.S.; Guimarães, F.S. The anxiolytic effects of cannabidiol in chronically stressed mice are mediated by the endocannabinoid system: Role of neurogenesis and dendritic remodeling. Neuropharmacology 2018, 135, 22-33. [CrossRef]

41. Ho, Y.S.; Byung-Hak, K.; Sang-Kyu, Y.; Myoung-Hwan, K. Chronic non-social stress affects depressive behaviors but not anxiety in mice. Korean J. Physiol. Pharmacol. Off. 2014, 18, 263-268.

42. Yingcong, Y.; Rui, W.; Chunbai, C.; Xia, D.; Lina, R.; Jiao, S.; Jianxin, L.; Lu, Z.; O’Donnell, J.M.; Jianchun, P. Antidepressant-like effect of trans-resveratrol in chronic stress model: behavioral and neurochemical evidences. J. Psychiatr. Res. 2013, 47, 315-322.

43. Huang, Y. Pre-gestational stress reduces the ratio of 5-HIAA to 5-HT and the expression of 5-HT1A receptor and serotonin transporter in the brain of foetal rat. Bmc Neurosci. 2012, 13, 22. [CrossRef]

44. Ying, X.; Ku, B.S.; Yao, H.Y.; Lin, Y.H.; Xing, M.; Zhang, Y.H.; Li, X.J. Antidepressant effects of curcumin in the forced swim test and olfactory bulbectomy models of depression in rats. Pharmacol. Biochem. Behav. 2005, 82, 200-206.

45. Mineur, Y.S.; Adetokunbo, O.; Wigestrand, M.B.; Fote, G.M.; Calarco, C.A.; Li, A.M.; Picciotto, M.R. Cholinergic signaling in the hippocampus regulates social stress resilience and anxiety- and depression-like behavior. Proc. Natl. Acad. Sci. U. S. A. 2013, 110, 3573-3578. [CrossRef]

46. Duncan, J.W.; Zhang, X.; Wang, N.; Johnson, S.; Harris, S.; Udemgba, C.; Ou, X.M.; Youdim, M.B.; Stockmeier, C.A.; Wang, J.M. Binge ethanol exposure increases the Krüppel-like factor 11-monoamine oxidase (MAO) pathway in rats: Examining the use ofMAO inhibitors to prevent ethanol-induced brain injury. Neuropharmacology 2016, 105, 329-340. [CrossRef]

47. Kim, H.D.; Hesterman, J.; Call, T.; Magazu, S.; Keeley, E.; Armenta, K.; Kronman, H.; Neve, R.L.; Nestler, E.J.; Ferguson, D. SIRT1 Mediates Depression-Like Behaviors in the Nucleus Accumbens. J. Neurosci. Off. J. Soc. Neurosci. 2016, 36, 8441-8452. [CrossRef]

48. Holt, A.; Sharman, D.F.; Baker, G.B.; Palcic, M.M. A Continuous Spectrophotometric Assay for Monoamine Oxidase and Related Enzymes in Tissue Homogenates. Anal. Biochem. 1997, 244, 384-392. [CrossRef]

49. Zhi, K.K.; Yang, Z.D.; Shi, D.F.; Yao, X.J.; Wang, M.G. Desmodeleganine, a new alkaloid from the leaves of Desmodium elegans as a potential monoamine oxidase inhibitor. Fitoterapia 2014, 98, 160-165. [CrossRef]

50. Shuichi, C.; Tadahiro, N.; Midori, N.; Richards, M.C.; Chisato, W.; Hiroshi, K. Chronic restraint stress causes anxiety- and depression-like behaviors, downregulates glucocorticoid receptor expression, and attenuates glutamate release induced by brain-derived neurotrophic factor in the prefrontal cortex. Prog. Neuropsychopharmacol. Biol. Psychiatry 2012, 39, 112-119.

51. Fukumoto, K.; Toki, H.; Iijima, M.; Hashihayata, T.; Yamaguchi, J.I.; Hashimoto, K.; Chaki, S. Antidepressant Potential of (R)-Ketamine in Rodent Models: Comparison with (S)-Ketamine. J. Pharmacol. Exp. Ther. 2017, 361, 9-16. [CrossRef]

52. Guida, F.; Turco, F.; Iannotta, M.; De, G.D.; Palumbo, I.; Sarnelli, G.; Furiano, A.; Napolitano, F.; Boccella, S.; Luongo, L. Antibiotic-induced microbiota perturbation causes gut endocannabinoidome changes, hippocampal neuroglial reorganization and depression in mice. Brain Behav. Immun. 2017, 67, 230-245. [CrossRef] [PubMed]

53. Lawson, M.A.; Parrott, J.M.; Mccusker, R.H.; Dantzer, R.; Kelley, K.W.; O'Connor, J.C. Intracerebroventricular administration of lipopolysaccharide induces indoleamine-2,3-dioxygenase-dependent depression-like behaviors. J. Neuroinflammation 2013, 10, 1-9. [CrossRef]

54. Konsman, J.P. The Mouse Brain in Stereotaxic Coordinates; Paxinos, G., Franklin, K.B.J., Eds.; Academic Press: New York, NY, USA, 2001; Volume 28, ISBN 0-12-547637-X.

Sample Availability: Not available. 